\title{
The Effect of a Nutrition Education Program on Improving Hemoglobin A1C and Body Mass Index of Patients with Type 2 Diabetes Mellitus in Erbil City: A Non-randomized Clinical Trial
}

\author{
Hawraz F. Saadi ${ }^{1 *}$, Wali O. Omer ${ }^{2}$ \\ ${ }^{1}$ Director of Public Relation, Ministry of Health, Erbil, Kurdistan Region, Iraq, ${ }^{2}$ Department of Community Medicine, College of Medicine, \\ Hawler Medical University, Erbil, Kurdistan Region, Iraq
}

\author{
${ }^{*}$ Corresponding author: \\ Hawraz F. Saadi, \\ Director of Public Relation, \\ Ministry of Health, Erbil, \\ Kurdistan Region, Iraq. \\ E-mail: hawraz1983@gmail. \\ com
}

Received: 01 November 2019

Accepted: 10 February 2020

Published: 30 June 2020

DOI

10.25156/pti.v10n1y2020.pp25-31

\section{A B S TR A C T}

Due to remarkable changes in lifestyles, there has recently been an increase in the prevalence of diabetes mellitus (DM) among individuals of all age ranges in both developed and developing countries. Changing the patients' lifestyles by modifying their diet through nutrition education programs decreases their body mass index (BMI), hemoglobin $\mathrm{A} 1 \mathrm{c}\left(\mathrm{HbA}_{1 \mathrm{c}}\right)$, and reverses $\mathrm{DM}$. This study aimed to determine the effect of a proposed nutrition education program on BMI and $\mathrm{HbA}_{1 \mathrm{c}}$ among patients with type 2 DM (T2DM). The present clinical trial was conducted on 42 patients with T2DM in Diabetes Center in Erbil-Kurdistan Region-Iraq, from December 2018 to September 2019. Data were collected using a customs questionnaire before the study and after educational sessions in which the patients were educated about an appropriate diet based on a proposed nutrition education program. In the first session and after third session, the patients' $\mathrm{BMI}$ and $\mathrm{HbA}_{1 \mathrm{c}}$ were measured. According to the results, most of the patients aged $45-64$ years, a majority of the patients lived in urban areas $(95.2 \%)$, were illiterate $(33.3 \%)$, and were obese $(76.2 \%)$. Due to the nutrition education program, remarkable decrease was observed in the patients' high (BMI) and high $\mathrm{HbA}_{1 \mathrm{c}}$ and experienced a mean decrease of $(2.6 \%)$ from $34.0 \pm 5.6$ to $31.4 \pm 5.2$, and $\mathrm{HbA}_{1 \mathrm{c}}$ decreased about $(2.0 \%)$ on average from 8.9 \pm 1.9 to $6.9 \pm 0.9$. High $\mathrm{BMI}$ and high $\mathrm{HbA}_{1 \mathrm{c}}$ can be controlled and decreased through appropriate nutrition education programs.

Keywords: Types 2 diabetes mellitus; Reversing type 2 diabetes mellitus; Nutrition education program; Hemoglobin A1c; Body mass index

\section{INTRODUCTION}

As defined by American Diabetes Association (2014), diabetes mellitus (DM) refers to a group of metabolic diseases in which defects in insulin secretion, insulin action, or both result in hyperglycemia which is accompanied by various complications including long-term failure, damage, and dysfunction of blood vessels, heart, nerves, kidney, and eye (American Diabetes Association, 2014). Therefore, defective insulin resistance or secretion or both are always utilized in the etiology of DM. DM is generally classified into type $1 \mathrm{DM}$ (T1DM) and type $2 \mathrm{DM}$ (T2DM). T2DM is more common and characterized by hyperglycemia and insulin resistance (Rao et al., 2019).

Given the changes in lifestyles over the past 30 years, there has been a sharp rise in the prevalence of DM all over the world such that it is now regarded as a global health problem. According to the reports of the World Health Organization, diabetes prevalence among adults over the age of 18 years increased from $4.7 \%$ in 1980 to $8.5 \%$ in 2014 (Roglic, 2016). As expected by the International Diabetes Federation, there will be an increase of 2 folds in the number of diabetic patients in the Middle East and North Africa by the next 20 years, and diabetes prevalence in Iraq rose from 5\% in 1978 to 19.7\% in 2012 (Mansour and Al-Douri, 2015).

DM has been estimated to account for $12 \%$ of the whole health expenditure spent on health (Dagogo-Jack, 2016), and the global cost of diabetes in 2015 was reported to be 1.31 trillion US dollars (Bommer et al., 2017). As reported by Zhuo et al. (2013), the lifetime cost of treating diabetes for an American patient with T2DM is about 85,200 US dollars (Zhuo et al., 2013). In addition to the abovementioned complications and financial cost caused by DM, the World Health Organization reported that 
DM caused 1.6 million death in 2015 and referred to it as the seventh leading cause of death in 2016 (World Health Organization, 2019).

Insulin sensitivity in patients with T2DM can significantly be improved by changing nutritional style, which is referred to as reversing diabetes because T2DM is tightly related to nutrition and lifestyle (Sami et al., 2017). Most diabetic patients witness a gradual increase in their weight, blood sugar, and doses of medications, which can be reversed through nutrition education programs. Such programs can also lead to an improvement in neuropathy in the feet and legs and also reverse in heart disease (Barnard, 2007). Therapeutic patient education helps patients to play a remarkable role in their own treatment and improve the quality of their lives, leading to a decrease in weight and complications (Golay, 2006). According to research, therapeutic patient education is aimed at managing DM; improving psychosocial, lifestyle, and clinical outcomes; increasing the patients' knowledge and skills; and modifying their behavior (Coppola et al., 2016).

Given the high prevalence rate of DM in Iraq and the remarkable role of nutrition education in reversing the complications caused by T2DM, the present study was carried out to examine the effect of nutrition education program on body mass index (BMI) and hemoglobin A1c $\left(\mathrm{HbA}_{1 \mathrm{c}}\right)$ in patients with T2DM in Erbil City, the Kurdistan Region of Iraq.

\section{MATERIALS AND METHODS}

This clinical trial was carried out on patients with T2DM during December 2018 and September 2019. The number of patients was 37,386 diabetic patients who were registered in Layla Qasm Center for diabetes located in Erbil, the Kurdistan Region of Iraq by July 15, 2018. Of those patients, $83 \%$ were adults with T2DM and 17\% were diagnosed with T1DM. Out of the adult patients with T2DM, 42 were approached while visiting Layla Qasm Consultant Center as the study sample based on the inclusion criteria (understanding Kurdish very well and living in Erbil city center, applying Nutrition Education program at least 1 month) and exclusion criteria (difficulty in communication or learning, having a renal or cardiovascular impairment, $\mathrm{HbA}_{1 \mathrm{c}}<6$, pregnant women, and patient who applying program $<1$ month).

The sample size was estimated through the following formula:

$$
n=\frac{\left(Z_{\alpha}+Z_{\beta}\right)^{2} S D^{2}}{d^{2}}
$$

$n=$ required sample size,

$Z \alpha=1.96$ (5\% alpha error),
$Z_{\beta}=0.84$ ( $80 \%$ power $)$,

$S D=0.8$,

$d=0.5$, difference to be detected

$=(1.96+0.84) 2(0.8) 2 / 0.52$

$=20$ estimated sample size for each group

Since the study sample was not randomized, the estimated size was doubled, making it 40 patients. Moreover, 10\% was added to the estimated sample size to compensate for the probable loss to follow-up; therefore, the final sample size became 42 .

The required data were collected through customs designed a questionnaire on the $1^{\text {st }}$ day of the education program and in the $3^{\text {rd }}$ month after the program.

An education program which was based on proposed nutrition education program (Campbell et al., 1998; Jenkins et al., 2001; Hu, 2003; Kelemen et al., 2003; Robertson et al., 2003; Gardner et al., 2005; Lovejoy, 2005; Tucker et al., 2005; Qi et al., 2007; Lutsey et al., 2008; Tonstad et al., 2009; Kaushik et al., 2009; Newgard et al., 2009; Fuhrman et al., 2010; Carter et al., 2010; Sluijs et al., 2010; and Lagiou et al., 2012) was utilized to achieve the aims and objectives of the study.

The program contains the following information:

1. Salad with nuts is the main part of the meals.

2. Beans are the main dish of the meals.

3. Restriction of refined and processed food like (bread, rice, cheeses, cakes, and biscuits...)

4. Limited restriction of red meat (once a month).

5. Limited restriction of poultry and fish (once a week).

6. Limited restriction of fruit (three pieces a day).

The program consisted of the following steps:

1. The patients in groups of 4-7 attended a nutrition education program at the center for the first session.

2. During the first session, the educational program was introduced to the patients.

3. Afterward, verbal consent was obtained from the patients, and the nutrition education program was explained in detail to the participants in $2 \mathrm{~h}$.

4. Changes in medications taken by the patients were based on their response to the nutrition program in consultation with their physician.

5. All the information obtained from the patients were kept confidential.

6. The patients were encouraged to attend the educational session with their partner to increase compliance.

7. Sessions were held once or twice a week, and each session lasted an hour, followed by an hour of asking and answering questions.

8. The sessions were held in the Kurdish language. 
9. The patients' weight and height were measured.

10 . The $3^{\text {rd }}$ session was started with questions and answers, questionnaire completion, and measurement of weight.

The collected data were analyzed using Statistical Package for the Social Sciences (SPSS) version 23 with a paired t-test.

To take into account the ethical considerations, the study protocol was accepted by the Scientific and Higher Education Committee of College of Medicine, Hawler Medical University. Moreover, the required approval letter was retrieved from the Ethical Committee of College of Medicine. In addition, official acceptance letter was obtained from the Layla Qasm Center for Diabetes in Erbil City. Finally, oral informed consent was obtained from the patients whose information was encoded to confirm confidentiality.

\section{RESULTS}

The results of the present study showed that most of the patients belonged to the age groups 45-54 and 55-64, with respectively $45.2 \%$ and $28.6 \%$ of the cases, followed by the age group 35-44 with $21.4 \%$. It was seen that there were more females than males such that the female-to-male ratio was (1.2:1.0). Furthermore, almost all of the patients $(95.2 \%)$ were from urban areas. Regarding their education, one-third of them $(33.3 \%)$ were illiterate, followed by those with primary education $(28.57 \%)$, post-secondary education (23.8\%), and secondary education (14.3\%). In terms of their BMI, one-third $(33.3 \%)$ of the patients had their BMI from 30 to 34.9, 35 to 39.9 (28.6\%), and 40 and more $(14.3 \%)$; therefore, most of the patients were obese. Only 19\% were overweight were BMI (25-29.9) and 4.8\% had normal BMI (18.5-24.9). In addition, more than half of the patients $(57.1 \%)$ had been diagnosed with T2DM of $1-10$ years, $28.6 \%$ of them $11-20$ years, $9.5 \%$ of them $<1$ year, and $4.8 \%$ of them $21-30$ years [Table 1 ].

The results of the study showed that the proposed program was influential in decreasing the patients' BMI such that a mean decrease of 2.6 was seen in different age groups, genders, residents of urban and rural regions, different education levels, in different BMI groups, and different diagnosis durations. The total mean drop in their BMI was 2.6 from $34.0 \pm 5.6$ to $31.4 \pm 5.2$; according to the result, the nutrition education program led to a significant decrease in the BMI in patients with T2DM at a $P<0.001$ [Table 2 and Figure 1].

Analyzing the collected data in terms of the effect of the proposed nutrition education program on the patients'
Table 1: The study population's demographic characteristics

\begin{tabular}{|c|c|}
\hline Variables & No. (\%) \\
\hline \multicolumn{2}{|l|}{ Age groups (years) } \\
\hline $25-34$ & $1(2.4)$ \\
\hline $35-44$ & $9(21.4)$ \\
\hline $45-54$ & $19(45.2)$ \\
\hline $55-64$ & $12(28.6)$ \\
\hline $65-74$ & $1(2.4)$ \\
\hline \multicolumn{2}{|l|}{ Gender } \\
\hline Female & $23(54.8)$ \\
\hline Male & $19(45.2)$ \\
\hline \multicolumn{2}{|l|}{ Place of residency } \\
\hline Rural & $2(4.8)$ \\
\hline Urban & $40(95.2)$ \\
\hline \multicolumn{2}{|l|}{ Education } \\
\hline Illiterate & 14 (33.3) \\
\hline Primary & $12(28.6)$ \\
\hline Secondary & $6(14.3)$ \\
\hline Post-secondary & $10(23.8)$ \\
\hline \multicolumn{2}{|l|}{ Body mass index } \\
\hline $18.5-24.9$ & $2(4.8)$ \\
\hline $25-29.9$ & $8(19)$ \\
\hline $30-34.9$ & 14 (33.3) \\
\hline $35-39.9$ & $12(28.6)$ \\
\hline 40 and more & $6(14.3)$ \\
\hline \multicolumn{2}{|c|}{ Diagnosed duration (year) } \\
\hline$<1$ & $4(9.5)$ \\
\hline $1-10$ & $24(57.1)$ \\
\hline $11-20$ & $12(28.6)$ \\
\hline $21-30$ & $2(4.8)$ \\
\hline \multicolumn{2}{|l|}{ Over all } \\
\hline Total no. & $42(100)$ \\
\hline
\end{tabular}

$\mathrm{HbA}_{1 \mathrm{c}}$ revealed that the program led to a remarkable decrease in the patients' $\mathrm{HbA}_{1 \mathrm{c}}$ in all studied groups, the total mean decrease in $\mathrm{HbA}_{1 \mathrm{c}}$ was 2.0 from $8.9 \pm 1.9$ to $6.9 \pm$ 0.9; according to the result, the nutrition education program led to a significant decrease in the $\mathrm{HbA}_{1 \mathrm{c}}$ in patients with T2DM with $P<0.001$ [Table 3 and Figure 2].

\section{DISCUSSION}

To figure out the effects of a nutrition education program on reversing T2DM, 42 patients with T2DM were recruited and trained using a nutrition education program. According to the results, most of the patients $(73.8 \%)$ were aged 45-64 years. This finding is in line with those of the study conducted by Suastika et al. (2012) who reported that middle age is a risk factor for T2DM. Similarly, Wild et al. (2004) pointed out that diabetes is more frequent among 
Table 2: The effect of the education program on the patients' BMI (pre-post program)

\begin{tabular}{|c|c|c|c|c|c|}
\hline Variables & No & Mean BMI (Pre)-SD & Mean BMI (Post)-SD & Mean differences & $P$ value \\
\hline \multicolumn{6}{|l|}{ Age groups (years) } \\
\hline $25-34$ & 1 & 24.7 & 24.7 & - & \\
\hline $35-44$ & 9 & 34.5 & 30.2 & 4.3 & \\
\hline $45-54$ & 19 & 32.8 & 30.8 & 2.0 & \\
\hline $55-64$ & 12 & 36.1 & 33.3 & 2.7 & \\
\hline $65-74$ & 1 & 38.1 & 36.5 & 1.6 & \\
\hline \multicolumn{6}{|l|}{ Gender } \\
\hline Female & 23 & 34.7 & 32.1 & 2.6 & \\
\hline Male & 19 & 33.2 & 30.5 & 2.7 & \\
\hline \multicolumn{6}{|l|}{ Place of residency } \\
\hline Rural & 2 & 39.1 & 35.9 & 3.2 & \\
\hline Urban & 40 & 33.8 & 31.2 & 2.6 & \\
\hline \multicolumn{6}{|l|}{ Education } \\
\hline Illiterate & 14 & 36.6 & 33.3 & 3.3 & \\
\hline Primary & 12 & 33.0 & 30.9 & 2.1 & \\
\hline Secondary & 6 & 32.5 & 29.1 & 3.4 & \\
\hline Post-secondary & 10 & 32.6 & 30.7 & 1.9 & \\
\hline \multicolumn{6}{|l|}{ Body mass index } \\
\hline $18.5-24.9$ & 2 & 24.1 & 24.1 & - & \\
\hline $25-29.9$ & 8 & 28.0 & 26.5 & 1.5 & \\
\hline $30-34.9$ & 14 & 32.1 & 30.0 & 2.1 & \\
\hline $35-39.9$ & 12 & 37.3 & 33.0 & 4.3 & \\
\hline 40 and more & 6 & 43.3 & 40.4 & 2.9 & \\
\hline \multicolumn{6}{|c|}{ Diagnosed duration (year) } \\
\hline$<1$ & 4 & 32.9 & 30.1 & 2.8 & \\
\hline $1-10$ & 24 & 34.0 & 31.5 & 2.5 & \\
\hline $11-20$ & 12 & 34.9 & 31.9 & 3.0 & \\
\hline $21-30$ & 2 & 31.4 & 29.7 & 1.7 & \\
\hline \multicolumn{6}{|l|}{ Overall } \\
\hline Total no. & 42 & $34.0 \pm 5.6$ & $31.4 \pm 5.2$ & 2.6 & $<0.001$ \\
\hline
\end{tabular}

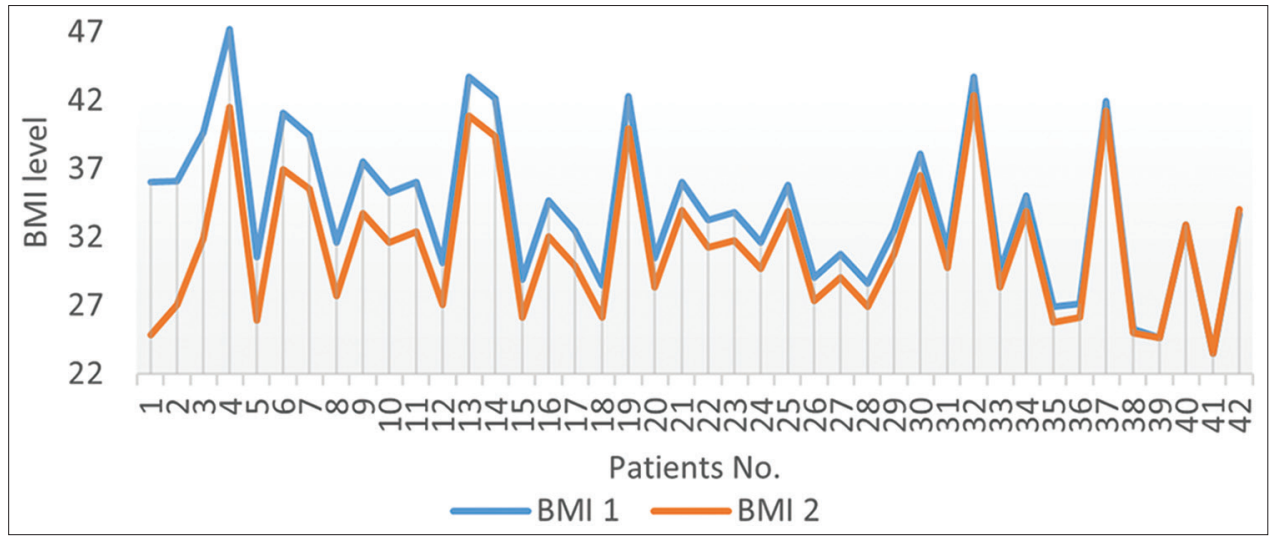

Figure 1: Change in the patients' body mass index (BMI) before and after the Nutrition Education Program (BMI 1 before-program, BMI 2 after-program)

individuals aged between 45 and 64 years. It was also observed that T2DM is more prevalent among the females. Almost similarly, Kautzky-Willer et al. (2016) stated that
T2DM is more frequently diagnosed at lower ages and BMI in men, while the most frequent T2DM risk factor, that is, obesity, is more common in females. 
Table 3: The effect of the education program on the patients' HbA $c$

\begin{tabular}{|c|c|c|c|c|c|}
\hline Variables & No & Mean $\mathrm{HbA}_{1 \mathrm{c}} \%$ (Pre)-SD & Mean $\mathrm{HbA}_{1 \mathrm{c}} \%$ (Post)-SD & Mean differences & $P$ Value \\
\hline \multicolumn{6}{|l|}{ Age groups (years) } \\
\hline $25-34$ & 1 & 8.6 & 6.4 & 2.2 & \\
\hline $35-44$ & 9 & 9.8 & 6.6 & 3.2 & \\
\hline $45-54$ & 19 & 8.7 & 6.9 & 1.8 & \\
\hline $55-64$ & 12 & 8.5 & 7.0 & 1.5 & \\
\hline $65-74$ & 1 & 10.0 & 8.5 & 1.5 & \\
\hline \multicolumn{6}{|l|}{ Gender } \\
\hline Female & 23 & 8.5 & 7.2 & 1.3 & \\
\hline Male & 19 & 9.4 & 6.6 & 2.9 & \\
\hline \multicolumn{6}{|l|}{ Place of residency } \\
\hline Rural & 2 & 7.7 & 6.9 & 0.9 & \\
\hline Urban & 40 & 9.0 & 6.9 & 2.1 & \\
\hline \multicolumn{6}{|l|}{ Education } \\
\hline Illiterate & 14 & 8.8 & 7.1 & 1.7 & \\
\hline Primary & 12 & 9.1 & 6.9 & 2.2 & \\
\hline Secondary & 6 & 9.8 & 6.9 & 2.9 & \\
\hline Post-secondary & 10 & 8.3 & 6.6 & 1.7 & \\
\hline \multicolumn{6}{|l|}{ Body mass index } \\
\hline $18.5-24.9$ & 2 & 11.2 & 6.5 & 4.7 & \\
\hline $25-29.9$ & 8 & 8.1 & 7.3 & 0.8 & \\
\hline $30-34.9$ & 14 & 8.2 & 6.7 & 1.5 & \\
\hline $35-39.9$ & 12 & 10.4 & 7.0 & 3.4 & \\
\hline 40 and more & 6 & 8.1 & 7.0 & 1.0 & \\
\hline \multicolumn{6}{|c|}{ Diagnosed duration (year) } \\
\hline$<1$ & 4 & 9.4 & 6.9 & 2.6 & \\
\hline $1-10$ & 24 & 8.7 & 6.5 & 2.2 & \\
\hline $11-20$ & 12 & 9.4 & 7.7 & 1.7 & \\
\hline $21-30$ & 2 & 7.8 & 7.2 & 0.6 & \\
\hline \multicolumn{6}{|l|}{ Overall } \\
\hline Total no. & 42 & $8.9 \pm 1.9$ & $6.9 \pm 0.9$ & 2.0 & $<0.001$ \\
\hline
\end{tabular}

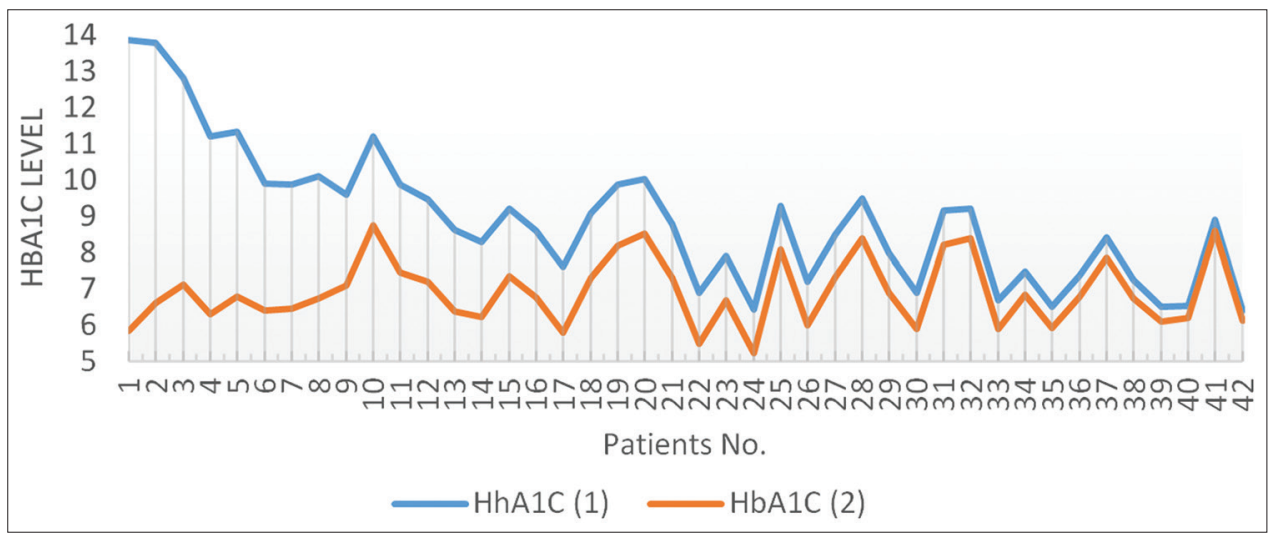

Figure 2: Change in the patients' hemoglobin A1c (HbA1c) before and after the Nutrition Education Program (HbA1c 1 before-program, HbA1c 2 After-program)

The results indicated that most of the patients resided urban areas. This finding is in good agreement with the results of the study carried out by Anjana et al. (2011) who reported a higher prevalence of diabetes among urban population. Diabetes was also found to be more prevalent among illiterate individuals and those with lower levels of education. Similarly, Bharati et al. (2011) observed that diabetes is more common among illiterate 
and obese individuals with a positive family history. According to the results, a large number of the diabetic patients $(76.2 \%)$ were obese (BMI $\geq 30)$. This finding is in good agreement with the results of the study conducted by Al-Goblan et al. (2014) who sought the mechanism linking obesity and DM.

According to the results, the proposed nutrition program was found to be effective in decreasing the diabetic patients' BMI in all studied age groups such that the overall mean decrease in the patients' BMI was 2.6 in the end of the study. Similar to the present study, Pot et al. (2019) studied the effect of nutrition and lifestyle intervention on significant parameters in T2DM and concluded that their proposed nutrition education program led to a mean decrease of $-1.70 \mathrm{~kg} / \mathrm{M}^{2}$ in the diabetic patients. Moreover, Di Onofrio et al. (2018) studied the effects of nutrition motivational intervention in patients with T2DM and concluded that the patients' BMI improved significantly after the intervention. Other studies have also reported the effect of nutrition education program on decreasing BMI among diabetic patients (Poeta et al., 2013; Gray, 2015; and Gray et al., 2015). Similarly, the results of a 5 -year longitudinal study of the effects of a structured dietary revealed that the T2DM patients' BMI decreased by (1.4) (Trento et al., 2004).

The results of the study also demonstrated that the proposed nutrition program led to a total mean decrease of (2.0) in the T2DM patients' $\mathrm{HbA}_{1 c^{\circ}}$ Glycated hemoglobin was found to decrease in all groups including age groups, both genders, urban and rural residents, education groups, individuals with different levels of BMI, and different diagnosis durations. The highest level of decrease in $\mathrm{HbA}_{1 \mathrm{c}}$ was seen in the patients with BMI of 18.5-24.9. Similarly, Liu et al. (2015) reported that their proposed nutrition program led to improvement in the patients' $\mathrm{HbA}_{1 \mathrm{c}}(\mathrm{Liu}$ et al., 2015). Mottalib et al. (2018) studied the impact of nutrition intervention on $\mathrm{HbA}_{1 \mathrm{c}}$ and cardiovascular disease risk factors in obese and overweight patients with T2DM. They concluded that the proposed nutrition program resulted in a remarkable decrease of about 0.3 to 1.03 in the patients' $\mathrm{HbA}_{1 \mathrm{c}}$. $\mathrm{HbA}_{1 \mathrm{c}}$ has been reported to drop as a result of other interventions including self-care intervention (Kazeminezhad et al., 2018) and medical nutrition therapy (Pastors et al., 2002).

\section{CONCLUSION}

T2DM can be reversed and controlled by nutrition education programs through decreasing in the $\mathrm{HbA}_{1 \mathrm{c}}$ and decreasing BMI.

\section{REFERENCES}

Al-Goblan, A. S., M. A. Al-Alfi and M. Z. Khan. 2014. Mechanism linking diabetes mellitus and obesity. Diabetes Metab. Syndr. Obes. 7: 587-91.

American Diabetes association. 2014. Diagnosis and Classification of Diabetes Mellitus. Diabetes Care. 37: S81-S90.

Anjana, R. M., R. Pradeepa, M. Deepa, M. Datta, V. Sudha, R. Unnikrishnan, A. Bhansali, S. R. Joshi, P. P. Joshi, C. S. Yajnik, V. K. Dhandhania, L. M. Nath, A. K. Das, P. V. Rao S. V. Madhu, D. K. Shukla, T. Kaur, M. Priya, E. Nirmal, S. J. Parvathi, S. Subhashini, R. Subashini, M. K. Ali and V. Mohan. 2011. Prevalence of diabetes and prediabetes (impaired fasting glucose and/or impaired glucose tolerance) in urban and Rural India: Phase I results of the Indian Council of Medical Research-INdia DIABetes (ICMR-INDIAB) study. Diabetologia. 54: 3022-3027.

Barnard, N. D. 2007. Dr. Neal Barnard's Program for Reversing Diabetes. Rodale, New York.

Bharati, D. R., R. Pal, S. Kar, R. Rekha, T. V. Yamuna and M. Basu. 2011. Prevalence and determinants of diabetes mellitus in Puducherry, South India. J. Pharm. Bioallied Sci. 3(4); 513-518.

Bommer, C., E. Heesemann, V. Sagalova, J. Manne-Goehler, R. Atun, T. Bärnighausen and S. Vollmer. 2017. The global economic burden of diabetes in adults aged 20-79 years: A cost-of-illness study. Lancet Diabetes Endocrinol. 5: 423-430.

Campbell, T. C., B. Parpia and J. Chen. 1998. Diet, lifestyle, and the etiology of coronary artery disease: the Cornell China study. Am. J. Cardiol. 82(10B): 18T-21T.

Carter, P. L. J. Gray, J. Troughton, K. Khunti and M. J. Davies. 2010. Fruit and vegetable intake and incidence of Type 2 diabetes mellitus: Systematic review and meta-analysis. BMJ. 341; c4229.

Coppola, A., L. Sasso, A. Bagnasco, A. Giustina and C. Gazzaruso. 2016. The role of patient education in the prevention and management of Type 2 diabetes: An overview. Endocrine. 53: 18-27.

Dagogo-Jack, S. 2016. Diabetes Mellitus in Developing Countries and Underserved Communities. Springer International Publishing, Berlin, Germany. p294.

Di Onofrio, V., F. Gallé, M. Di Dio, P. Belfiore and G. Liguori. 2018. Effects of nutrition motivational intervention in patients affected by Type 2 diabetes mellitus: A longitudinal study in Naples, South Italy. BMC Public Health. 18: 1181.

Fuhrman, J., B. Sarter, D. Glaser S. Acocella. 2010. Changing perceptions of hunger on a high nutrient density diet. Nutr. J. 9: 51.

Gardner, C. D., A. Coulston, L. Chatterjee, A. Rigby, G. Spiller and J. W. Farquhar. 2005. The effect of a plant-based diet on plasma lipids in hypercholester olemic adults: A randomized trial. Ann. Intern. Med. 142(9): 725-733.

Golay, A. 2006. Dietary and body weight control: Therapeutic education, motivational interviewing and cognitive-behavioral approaches for long-term weight loss maintenance. Nestle Nutr. Workshop Ser. Clin. Perform. Programme. 11: 127-137.

Gray, A. 2015. Nutritional Recommendations for Individuals with Diabetes. Lilly USA: Senior Clinical Research Scientist.

Gray, N., G. Picone, F. Sloan and A. Yashkin. 2015. Relation between $\mathrm{BMI}$ and diabetes mellitus and its complications among US older adults. South. Med. J. 108(1): 29-36.

$\mathrm{Hu}$, F. B. 2005. Associations of dietary protein with disease and mortality in a prospective study of postmenopausal women. Am. 
J. Epidemiol. 161(3): 239-249.

Jenkins, D. J., C. W. Kendall, D. G. Popovich, E. Vidgen, C. C. Mehling, V. Vuksan, T. P. Ransom, A. V. Rao, R. Rosenberg-Zand, N. Tariq, P. Corey, P. J. Jones, M. Raeini, J. A. Story, E. J. Furumoto, D. R. Illingworth, A. S. Pappu and P. W. Connelly. 2001. Effect of a very-high-fiber vegetable, fruit, and nut diet on serum lipids and colonic function. Metabolism. 50(4): 494-503.

Kaushik, M., D. Mozaffarian, D. Spiegelman, J. E. Manson, W. C. Willett and F. B. Hu. 2009. Long-chain omega-3 fatty acids, fish intake, and the risk of Type 2 diabetes mellitus. Am. J. Clin. Nutr. 90: 613-620.

Kautzky-Willer, A., J. Harreiter and G. Pacini. 2016. Sex and gender differences in risk, pathophysiology and complications of Type 2 diabetes mellitus. Endocr. Rev. 37(3): 278-316.

Kazeminezhad, B., H. Taghinejad, M. Borji and A. Tarjoman. 2018. The effect of self-care on glycated hemoglobin and fasting blood sugar levels on adolescents with diabetes. J. Compr. Pediatr, 9(2): e62661.

Kelemen, L. E., L. H. Kushi, D. R. Jacobs and J. R. Cerhan. 2003. Plant-based foods and prevention of cardiovascular disease: An overview. Am. J. Clin. Nutr. 78(3 Suppl): 544S-551S.

Lagiou, P., S. Sandin, M. Lof, D. Trichopoulos, H. O. Adami and E. Weiderpass. 2012. Low carbohydrate high protein diet and incidence of cardiovascular diseases in Swedish women: Prospective cohort study. BMJ. 344: e406.

Liu, H., M. Zhang, X. Wu, C. Wang and Z. Li. 2015. Effectiveness of a public dietitian-led diabetes nutrition intervention on glycemic control in a community setting in China. Asia Pac. J. Clin. Nutr. 24(3): 525-532.

Lovejoy, J. C. 2008. The impact of nuts on diabetes and diabetes risk. Curr. Diab. Rep. 5(5): 379-384.

Lutsey, P. L., L. M. Steffen and J. Stevens. 2008. Dietary intake and the development of the metabolic syndrome. The atherosclerosis risk in communities study. Circulation. 117: 754-761.

Mansour, A. and F. Al-Douri. 2015. Diabetes in Iraq: Facing the epidemic. A systematic review. Wulfenia. 22: 258.

Mottalib, A., V. Salsberg, B. N. Mohd-Yusof, W. Mohamed, P. Carolan, D. M. Pober, J. Mitri and O. Hamdy. 2018. Effects of nutrition therapy on $\mathrm{HbA} 1 \mathrm{c}$ and cardiovascular disease risk factors in overweight and obese patients with Type 2 diabetes. Nutr. J. 17(1): 42.

Newgard, C. B., J. An, J. R. Bain, M. J. Muehlbauer, R. D. Stevens, L. F. Lien, A. M. Haqq, S. H. Shah, M. Arlotto, C. A. Slentz, J. Rochon, D. Gallup, O. Ilkayeva, B. R. Wenner, W. S. Jr. Yancy, H. Eisenson, G. Musante, R. S. Surwit, D. S. Millington, M. D. Butler and L. P. Svetkey. 2009. A branched-chain amino acid-related metabolic signature that differentiates obese and lean humans and contributes to insulin resistance. Cell Metab. 9(4): 311-326.

Pastors, J. G., H. Warshaw, A. Daly, M. Franz and K. Kulkarni. 2002. The evidence for the effectiveness of medical nutrition therapy in diabetes management. Diabetes Care. 25: 608-613.

Poeta, L. S., M. F. S. Duarte, B. Caramelli, J. Mota and I. C. B. Giuliano. 2013. Effects of physical exercises and nutritional guidance on the cardiovascular risk profile of obese children.
Rev. Assoc. Med. Bras. 59(1): 56-63.

Pot, G. K., M. C. Battjes-Fries and O. N. Patijn, H. Pijl, R. F. Witkamp, M. de Visser, N. van der Zijl, M. de Vries, P. J. Voshol. 2019. Nutrition and lifestyle intervention in Type 2 diabetes: Pilot study in the Netherlands showing improved glucose control and reduction in glucose lowering medication. BMJ Nutr. Prevent. Health. 1: 1-12.

Qi, L., R. N. Van Dam and F. B. R. Khu. 2007. Heme iron from diet as a risk factor for coronary heart disease in woman with Type 2 diabetes. Diabetes Care. 30(1): 101-106.

Rao, N., x. Wang, Y. Zhai, J. Li, J. Xie, Y. Zhao and L. Ge. 2019. Stem cells from human exfoliated deciduous teeth ameliorate Type II diabetic mellitus in Goto-Kakizaki rats. Diabetol. Metab. Syndr. 11(22): 11

Robertson, M. D., J. M. Currie, L. M. Morgan, D. P. Jewell and K. N. Frayn. 2003. Prior short-term consumption of resistant starch enhances postprandial insulin sensitivity in healthy subjects. Diabetologia. 46(5):659-665.

Roglic, G. 2016. WHO Global report on diabetes: A summary. Int. J. Non-Commun. Dis. 1: 184853.

Sami, W., T. Ansari, N. S. Butt and M. R. Ab Hamid. 2017. Effect of a diet on Type 2 diabetes mellitus: A review. Int. J. Health Sci. (Qassim). 11: 171-177.

Sluijs, I., J. W. Beulens, A. D. L. van der, A. M. Spijkerman, D. E. Grobbee and Y. T. van der Schouw. 2010. Dietary intake of total animal and vegetable protein and risk of Type 2 diabetes in the European prospective investigation into cancer and nutrition (EPIC)-NL study. Diabetes Care. 33: 43-48.

Suastika, K., P. Dwipayana, M. S. Semadi and R. A. Kuswardhani. 2012. Age is an important risk factor for Type 2 diabetes mellitus and cardiovascular diseases. In: Chackrewarthy S, editor. Glucose Tolerance. InTech, Croatia. p67-80.

Tonstad, S., T. Butler, R. Yan and G. E. Fraser. 2009. Type of vegetarian diet, body weight, and prevalence of Type 2 diabetes. Diabetes Care. 32: 791-796.

Trento, M., P. Passera, E. Borgo, M. Tomalino, M. Bajardi, F. Cavallo and M. Porta. 2004. A 5-year randomized controlled study of learning, problem solving ability and quality of life modifications in people with Type 2 diabetes managed by group care. Diabetes Care. 27(3): 670-675.

Tucker, K. L., J. Hallfrisch, N. Qiao, D. Muller. R. Andres, J. L. Fleg and Baltimore Longitudinal Study of Aging. 2005. The combination of high fruit and vegetable and low saturated fat intakes is more protective against mortality in aging men than is either alone: The Baltimore longitudinal study of aging. J. Nutr. 135(3): 556-561.

Wild, S., G. Roglic, A. Green, R. Sicree and H. King. 2004. Global prevalence of diabetes: Estimates for the year 2000 and projections for 2030. Diabetes Care. 27(5): 1047-1053.

World Health Organization. 2019. Diabetes. Geneva. Available from: https://www.who.int/news-room/fact-sheets/detail/diabetes. [Last accessed on 2019 Aug 25].

Zhuo, X., P. Zhang and T. J. Hoerger. 2013. Lifetime direct medical costs of treating Type 2 diabetes and diabetic complications. Am. J. Prev. Med. 45: 253-261. 